able to a too full enjoyment of the privileges of health and of the good things of this life. Thus his attention is now drawn by the patient to a different clinical condition, and this enlarging display of minor suffering may be one reason why nervous disorders are supposed to be more prevalent.

But in other directions also-including that of public health -important work awaits our highly trained students. A system of almost universal life assurance under State supervision, analogous to that which has been largely introduced into Germany, does not exist in this country; but if it were to become established among us it would make a considerable addition to professional work, in connection with the examination of candidates. Certificates of sound health and of freedom from contagious, and in particular from any tuberculous taint, will be more in request as the public becomes more educated in matters of hygiene, and more sensitive as to the risks of the dissemination of phthisis. For the selection of careers the profession is already largely consulted, and the State exacts qualifying medical examinations for the Services; but in this direction there is room for much more work than is at present done.

The soundness of future generations, and the exclusion of heritable disease, are duties which may not be mentioned, yet lie dormant near the conscience of the profession. But the profession is not anxious to invite any responsibility of this sort.

And again, on the subject of practical Malthusianism, which is probably opposed by the conscience of the profession as a false notion, politically, socially, and morally, its attitude has also been one of reserve. It has, I believe, always been in favour of the principles which are consonant with the best interests of humanity and with the greatest sum of happiness and power.

More advice will be needed by the State than has been hitherto taken, or at any rate acknowledged, by it in regard to ethnological and colonising questions-a mere sample of the large department of State work in which the profession is destined to take a share.

\section{Compulsory Education.}

The medical supervision of education is another important question which affords considerable scope for professional activity. Where so many children are congregated, and where parents are deprived of all means of seiecting associates for them, a serious onus is incurred by the State, and nothing short of the greatest care can cover its responsibilities.

The fatal transmission of scarlet fever and of diphtheria is the worst evil, and the question arises whether anything further might be done to prevent their spread. Are all children who are allowed to return to their schools after an attack of diphtheria sufficiently disinfected in one of the most likely directions? The nasal cavities, which are nearest to the seat of affection, and in themselves often affected by the disease, may sometimes be overlooked as a persistent nidus. Again, it is since the children of the poorest have been forced into the Board schools, in the company of children of respectable and cleanly artisans, that vermin has invaded homes carefully kept, and that the health, or even the life, of many a delicate child has been sacrificed. All this is preventable by insisting that the hair of all children under a certain age attending these schools shall be kept short.

The Changes which have occurred in the Conditions of Practice.

Whilst disease has greatly diminished, treatment has grown, and is on the increase ; and the labour of treatment is greater than at any previous time. This is true both for the general practitioner and also for the hospital physician and surgeon.

\section{The Restlessness of Patients.}

In the behaviour of those who are compelled to consult us there is noticed a restlessness in their desire for the advice of various authorities, and a corresponding instability in the relationship between them and their medical adviser, which is much to the disadvantage of both. There is an old saying that " it is much easier to treat the patient than to treat the patient's friends," who often speak with an assurance about medical matters which is generally proportionate to their ignorance of the subject, and which it is particularly difficult to overcome. A patient who needed only to trust and persevere on the well-considered lines which had been laid down may thus be passed from hand to hand, with little chance of benefit, and without any chance of carrying out the systematic treatment which is necessary. In this way the field of practice has been lessened for the family attendant, often to the detriment of his patients. But other causes have also led to a diminution of his opportunities. Too often the patient is mistaken as to his own troubles, and his most obvious symptom, that which attracts his notice, may be but a small part of the case. Nothing will satisfy him till he has had the opinion of someone who has a reputation in reference to the particular system which has caught his attention; and this is a process apt to be repeated indefinitely. By the concentration of the specialist's observation upon this prominent symptom, the important and essential elements of the case may pass unnoticed, a risk capable of avoidance had his adviser, familiar with his conditions, been at hand to reveal the less obvious essentials to a complete diagnosis.

Thus the patient's advantage lies in a co-operation between his regular medical attendant and his occasional adviser; but this also works for their advantage and comfort. The cultivation of this mutual professional intercourse tends to strengthen the bond of professional brotherhood; and well might we say, in the words of a great physician, "When doctors differ who shall decide; but when doctors agree who shall venture to differ?" This reminds us that combination is that which we must look to to ease many of our difficulties, and it is a remedy which brings with it pleasure as well as strength.

\section{A CARDIO-PULMONARY MURMUR ; OR A RESPIRATORY MURMUR RHYTHMICAL WITH THE HEART BEATS.}

By J. EDWARD SQUIRE, M.D., M.R.C.P., D.P.H., Physician'to the North London Hospital for Consumption
and Diseases of the Chest.

IN March, I895, I had the good fortune to be in the chair when Dr. William Ewart read an interesting paper, on the Dorsal Auscultation of Heart Sounds and Murmurs, before the Harveian Society. In opening the discussion I took occasion to make the following remark $^{1}$ :In reference to murmurs heard in the back, there was a murmur, systolic in point of time, which was well heard just below the angle of the scapula and sometines in other situations, and tubes, and, therefore, not strictly cardiac, though caused by the beating of and heard during inspiration or only during this act. It was was

I subsequently collected a good number of cases illustrating this murmur, but unfortunately sixteen months ago an attack of scarlet fever caught me with the notebook containing the references to these cases in my pocket, and disinfection destroyed the germs of an article on the subject, as well as any microbes. I have, however, been able to find notes of some of of the cases and have added others within the past few months.

In examination of the chest it is noticeable how, in certain conditions of the lungs, the heart sounds may be heard in parts far removed from the cardiac area. Consolidation from whatever cause conducts sound from the heart or from large vessels to the surface of the chest, so that such sounds are heard in unexpected places, and when so heard, furnish valuable information as to the interposed organ. Thus we may have the heart sounds conducted towards the right apex in tuberculous disease of the lung of that side, and we may hear the heart sounds clearly in any part of the chest wall over the position of a good-sized lung cavity. When, therefore, we hear sounds corresponding in rhythm to the beat of the heart, at some distance from that organ, or from any large vessel, we are at once led to suspect that there is some consolidation of the intervening lung.

There is, however, as I have already indicated, a source or fallacy, which, though frequently present, has received little notice from writers and is perhaps less recognised than it should be. It, however, deserves wider recognition; for the physical sign of which I speak may, if misinterpreted, mis- 
lead not only as to the condition of the lungs, but also as to the condition of the heart. This physical sign is in fact a bruit, rhythmical with the heart beat, but produced in the lung -a respiratory sound which may easily be mistaken for a conducted cardiac sound. Heard, as it may be, at some distance from the heart or great vessels, it might convey an erroneous impression of the state of the lung: added to this, the character of the sound would certainly suggest some lesion of a valve of the heart if the sound were supposed to originate in this organ. The subject is therefore of importance, the more so that, as I have already mentioned, it is not of rare occurrence. I propose in this article to instance some cases in illustration of the physical sign under consideration, and to discuss the causation of the sign and its significance.

The sign is a blowing bruit or whiff, generally high pitched but not always so, synchronous with the heart beat, and therefore rhythmical ; sometimes heard throughout both inspiration and expiration, but more frequently only audible during some portion of the respiratory cycle. The bruit, though simulating a blowing cardiac or arterial murmur, is as I shall show caused by the movement of air in the lungs and air tubes, though its rhythm is communicated by the movements of the heart, and perhaps sometimes by the distension of a large artery.

CASE I.-R. W. R., male, aged CASES. first seen in May 1892. Tulerculous deposit right apex.' In February, 8893 , I noted "a ligh-pitched blowing muymur synchronous with the heart beat (systolic) heard over the right side below the nipple level and into the right axilla." There was also a loud systolic murmur over the aortic cartilage during inspiration, absent during expiration. A month later the first murmur was " nearly gone," but still audible. The lung condition became quiescent, and the patient was in fairly good health when I saw him last year.

CASE II.-Mirs. G., 25, consulted me in 1894 with tuberculous consolidation at the right apex. On the left, at the base behind, there was a soft systolic murmur during inspiration only $:$ not heard over the cardiac area. Six months later the tuberculosis had become quiescent. There was a loud bruit de diable and arterial murinur in the neck, and a "systolic inspiratory murmur just inside the tip of the left scapuia." Heart sounds clear.
CASE III.-L. P. female, I6. Left pleurisy Christmas 1894 . In November, CASE III.-L. P., female, 16. Left pleurisy Christmas 1894. In November,
1895, she had cough with harsh breathing at the left apex. A loud systolic bruit was heard immediately below the tip of the left scapula, always present, but louder on inspiration. No murmur heard over the cardiac area. A fortnight later fine crepitations were noticed at theleft apex, and the bruit at the hase had disappeared.

CASE IV.-C. L., female, 19. Tuberculous deposit right ápex. Systolic "whiff" heard just below tip of left scapula, and in third space in front on right side. Bruit de diable in neck.

CASE v.-Mr. S., aged r9, clerk. Seen in 1895 with rather overacting heart, faint systolic murmur over pulmonary cartilage (second left), but no murmur over cardiac area. Apex beat just below nipple. Impulse
forcible. In left axilla and over left back up to about level of fourth forcible. In left axilla and over left back up to about level of fourth
dorsal spine, a systolic blowing murniur is heard only during inspiration (and chiefly during the latter part of this). It is a pulmonary (breath) sound and not a vascular sound.

CASE VI.-Mr. W., aged 2r, seen March, 1895 . Recovering from left basic pneumonia. A systolic murmur heard over left base belind, on inspiraion, not during expiration.

CASE VIr.-Miss McK, aged 2o. Anæmic : has had pleurisy twice at left base. Faint systolic murmur heard over left base, especially during inspiration. Hæmic bruit over cardiac area.

CASE VIII.-G. S. male, aged 25. Cold and cough (catarrh) four days. Much blackish plilegm. Later, systolic inspiratory whiff in left axilla.

CASE IX.-L. N., female, aged 27. Was in hospital under my care in 1895 with extensive tuberculous mischief of the left upper lobe. In October 1897, she came to see me. There was much cavitation of the left lung, and
extension of the disease to the right side. Whilst talking to the patient one notices a peculiar sound produced with the breathing: a blowing or

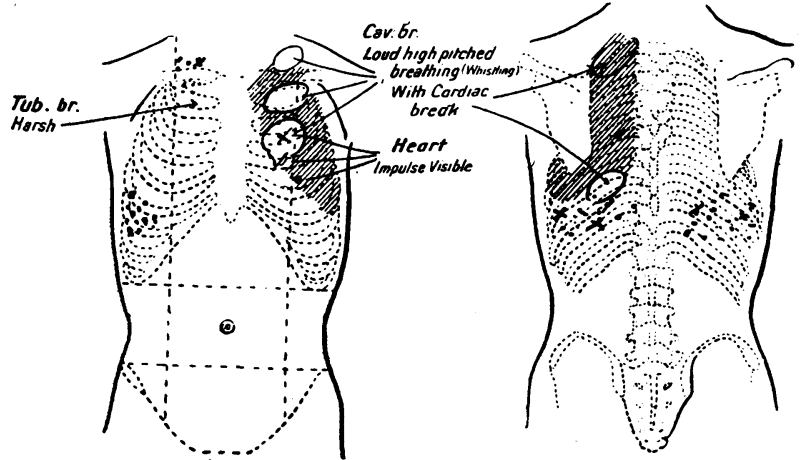

puffing noise is produced during inspiration and at the beginning of expiration, rhythmic with the heart beat. This can be heard at some distance (about 6 feet) from the patient. With the stethoscope this sound is
heard with greatest intensity under the left clavicle anteriorly, and just below the angle of the left scapula posteriorly. It is a dry, metallic puff, taking place at the same time as the first sound of the heart. The aecompanying diagram will show that there are

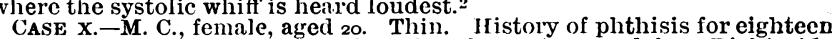
CASE X.- M. C., female, aged 2o. Thinl. History of phthisis for eighteen
months. Cavity left apex with deposit to base of upper lobe. Right side months. Cavity left apex with deposit to base of uppe

rec. Inspiratory whiff heard below the right clavicle.
CASE XI.-C. H. J., male, aged 20 . Phthisis nine months. Acute. Cavity in right apex with active softening; deposit to fourth rib in front and sixth spine behind. Har'sh, jerky respiration in left front to third space. Along the anterior axillary border on the left side a lespiratory murmur
(systolic) is heard during inspiration; absent during expiration. Breath (systolic) is heard during inspiration; absent during expiration. Breath sounds at this spot good; no whispering pectoriloquy. Heart sounds
quite clear. A week later systolic whiff in second space right above and quite clear. A week later systolic whiff in second space right above and
just within the nipple, chiefly inspiratory. Also similar sound, deeper in just within the nipple, ehiefly inspirator'y. Also similar sound, deeper in tone below angle of left scapula, chiefly expiratory. Whilf noted above all over the ieft front. very well marked just outside the apex of the heart. Chest is thin, flat, and poorly covered. $A$ week later the two whiffs noted above still plainly audible; that on the right seems now chiefly expiraabove still plainly audible; that on the right seems now chiefly expiraover heart or aorta.

CASE XII.-F. H., aged ${ }_{31}$, male. Admitted December ${ }_{3}$ Ist, 1897. Phthisisactive; deposit scattered throughout both lungs. Cavities in both apices; larynx affected. On right side a systolic blowing bruit is heard in second, third, and fourth spaces from border of sternum to mid-axilla an area as big as the hand. It is heard through both inspiration and expiration. sometimes missing one beat at end of expiration. Not conducted along aorta; aortic sounds clear. Threathiff goes on when patient is holding his breath, but then with to and fro sound-double. The res-

piratory systolic sound still heard as above three weeks later.
CASE xIII.-H. S., male, aged 34 . Fibroid phthisis-chronic. Heart CASE XIII.-H. S., male, aged 34. Fibroid phthisis-chronic. Heart socond space in the nipple line, also just inside the right seapula, here

CASE XIV.-S. S., female, aged ${ }_{36} 6$. Thin, poorly covered chest ; tuberculous deposit both apices, especially left. Chronic condition. Laryngeal papilloma in interarytenoid regions january 27 th. Systolic brint, of the interscapular region to just below the angle of the scapula; from of the interscapular region to just below the angle of the scapula; from there to the base, only the inspiratory part of the bruit is heard. and ninth spines, about tip of seapula; where it is only inspiratory. Heart sounds clear. CASE XV.-E. H. P. male, aged 47. Thin, poorly-covered chest. Fibroid
(chronic) phthisis, ulceration of epiglottis. January zoth. Systolic res(chronic) phthisis, ulceration of epiglottis. January 2 oth. Systolie res-
piratory whiff left front at level of nipple (fourth rib) during whole of peratiration only. Heart sounds at apex quite clear. March 3 rd. The expiration only. Heart sounds at apex quite clear. March 3 rd. The respiratory whiff is now heard very distinctly over the whole left riront heard over first two spaces on right front. On the front (both sides) the whiff is well marked during the wliole of expiration and doubtful during whiff is well marked during the whiole of expiration and doubtul during inspiration. At left base behind - below tip of scapula-a similar whiff heard only during inspiration. March 7 th. - Whiff heard when he hords his breath, either after inspiration or after expiration. Much louder in
latter. With the expiratory sound there is a distinct systolic bruit (wliff).
With the inspiration a sort of jerky respiratory sound, the interruptions being rhythmical with the heart beat, but greatest intensity postsystolic.

CASE XVI. -S. B., male, aged 2r. Three months' history, dating from inluenza in January, r898, followed by pleurisy-fluid to the sixth rib behind. March 1 th, 898 , left side clear. Left front, all over, inspiratory sound is loud and harsh and interrupted exply distinct systolic whiff. Heart beats. Expiratory sound mich sorter, with distinet systolic whifr.

sounds clear. No murmur's over either aorta or pulmonary artery.
CASE XVII.-A. A. W., male, aged 4I. Tuberculous deposit, left, to fourth CASE XVII.-A. A. W., male, aged 4 r. Tuberculous deposit, left to fourth
rib, January 6 th, r898. Systolic high pitched whiff only heard during inspiration. Heard in the third space just inside the nipple line, left side. arch 3 rd. Still whiff in third leit space as before. Below inner end of left clavicle there is cavernous breathing, with whispering pectoriloquy, and here the heart beat.
CAsE Xvir.-L. S., female. aged 20, shop assistant. March 23rd, 1898.
Palpitation and anæmia. Nothing pulmonary. Soft systolic murmurs Palpitation and anemia. Nothing pumonary. Sot systolic murmurs heard at cardiac apex and at the pulmonlry cartilage; orut the tip of the the neck. A systolic (respiratory from the cardiac murmur, being rougher and of lower pitch.

CASE XIX.-F. P., male, aged 18 (admitted March r7th, 1898), clerk. Ill seven months. Good deal of wasting. Tuberculous deposit in left lung both lobes). Slight consolidation right apex. In first and second spaces he breath sounds give a "rhythmical jerky inspiration" not synchronous with heart beats; but with expiration the in

and constitute an expiratory systolic whiff. CASE XX. $-\Lambda$. P., female, aged 32. Anamia and debility; no phthisis. Just above the cardiac area there is a systolic expiratory whint in of the sounds clear; beat forcible. Five minutes later, when heard.

CASE XXI.-J. M., male, aged 47. Fibroid lung with superadded tuberCASE XXI.-J. M., male, aged 47. Fibroid lung with superadded tuber-
culosis Very marked systolic respiratory murmur above cardiac area; culosis. out the whole respiratory cycle simulating a cardiac murmur.

Heart sounds clear.
CASE XXII.-Mr. R. G.. aged 49 . Has been twenty-seven years in India (Civil Service). Slight fibrosis of lung, but apparently notubercle. Systolic inspiratory whiff lieard below the tip of the right scapula, where there ar some dry

CASE XXIII-Occasionally when lying on my left side I can hear a highpitched whiff rilytlimical with the heart beats, which seems to come from the trachea. It occur's only towards the end of inspiration and seems to be rather after the heart beat (postsystolic). It continues when 1 hold my 
breath and is then heard with each beat of the heart. It is not heard when I am lying on my right side. Richardson's theory, referred to later's of a piece of lung being pressed between the heart and the chest-wall migh explain the effect of position on this whiff.

The cases noted above show auscultatory phenomena produced in the lung, and modified by the adjacent circulatory organs. We have other evidence that the sounds produced in one organ in the chest may be modified by the action of other organs in that"cavity. As an example of the modifying action of the respiratory system on vascular sounds the following case may be given.

CASE XXIV.-M. T., female, aged 22. Anæmia with enlargement of the thyroid, especially of the right lobe. In the root of the neck on the right side there is a continuous, high-pitched, mus:cal mul'mur (venous hum), which is much louder during inspiration. Here the negative pressure in the thorax during inspiration causes an increased flow through the vein with consequent intensification of the murmur.

Of the 23 cases illustrating the cardio-pulmonary murmur. 13 are males and 10 females. In 14 of the cases (9 males and 5 females) there was tuberculosis of the lung; in 9 (5 males and 4 females), there was no tubercle detected. The murmur was heard only during inspiration in so cases; only during expiration in 4 cases, and during both inspiration and expiration in 7 cases. In 2 cases the part of the respiratory cycle is not noted. It will be seen then that in this series of cases the murmur is most frequently inspiratory. It is not permanent sometimes being present at one examination, and not to be heard at another.

We may note that in Case II the bruit was distinctly audible over the position of the heart's apex, and was thus very liable to be taken for a cardiac murmur. In Case XIV the sound was heard down the left spinal groove along the course of the aorta. In both cases it was easily demonstrated by careful auscultation that there was no murmur in the heart or in the aorta. IIt will be observed that the lung condition varied greatly in the different cases. The bruit may be heard over a cavity and over apparently healthy lung. I have heard it in cases where there was no suggestion and no evidence of lung mischief ; and, given a certain laxity of tissues, a genera debility, I believe this bruit may be frequently found without disease of either lungs or heart. That most of the instances here recorded are in patients with lung disease is probably only due to the field of observation which my own practice chiefly affords.

As to the causation of the bruit under consideration it is clearly caused by the passage of air through the air tubes. It is only the ordinary respiratory murmur momentarily modified in intensity at the systole of the heart. Jerky respiratory sounds (cog-wheel breath sounds) are often heard in morbid states of the lung or as a result of nervousness; in the latter case the jerkiness is due to irregularity or want of smoothness in the action of the respiratory muscles.

The sound which I am now discussing is a form of jerky respiration, limited to a portion only of the lung, and due to a local cause. Its importance lies in the fact that the jerks, or inequality in the intensity of the respiratory murmur, occur at intervals corresponding to the beats of the heart-a rhythm which may cause the whiff, or breath-sound at its point of maximum intensity, to be mistaken for a cardiac murmur.

The simplest explanation of the influence of the heart beat on the respiratory murmur is that the heart kicks against portion of the lung and forces some air out of that portion. This would explain some of the bruits heard during expiration. The sudden pressure, which during expiration would momentarily intensify the breath sound and so produce this systolic whiff, would act somewhat differently during inspira tion. Alternating differences of pressure on a part of the lung in contact with the heart might produce jerkiness of the respiratory murmur in both inspiration and expiration, but in inspiration the greater intensity of the breath sound should coincide with the period of least pressure, and be cardio diastolic in time. I have not been able to satisfy myself that this is so, though in some cases the sound seemed to be postsystolic. Parts of the lung distant from the heart might be influenced by the movements of the heart if consolidated lung intervened; and pleural adhesions might cause movements in the vicinity of the heart to be felt in more distant parts of the lung. Similarly the alternating distension and recoil of a large artery might affect parts in direct contact, or, more rarely, at a distance.

I have little doubt that these considerations will explain the broad fact that breath sounds may be rhythmically modified in intensity by the movements of the heart, but I cannot pretend to explain the physical detail in all the various conditions in which this sign may be noticed.

A less common form of this modification of the breath sounds by the impulse of the heart is exemplified in the following case :-

CASE XXV.-A. F., male, aged I9. Large, over-acting heart, with mitral disease from rheumatic fever. The respiratory sounds are jerky all over both sides, back and front, with the rhythm of the heart beats. The interruptions are only noticeable during inspiration, and are especially distinct towards the end of inspiration. A murmur or whiff is thus produced, which is heard most clearly below the tip of the left scapula.

Here we see the connection of the whiff with the interrupted or jerky respiration which is sometimes noticed with an overacting heart. The occurrence of such jerky breath sounds is referred to in most textbooks on examination of the chest, and when, as in the foregoing case, the jerky respiration is heard all over the chest, its significance is not likely to be mis understood. When, however, the distinct whiff or murmur, which was here present below the left scapula, is alone audible, without jerky breathing elsewhere, there is more risk of mistaking the meaning of the sign.

There is little significance in the sign per se, though I believe it is always associated with a general debility. The real importance of a recognition of the origin of the murmur lies in the risk of mistaking it for a sign of disease of the heart valves, and of suspecting also some lung mischief from the apparent conduction of a cardiac murmur to a distant part.

It is not to be supposed that a physical sign which is so frequently present should have hitherto escaped notice, but I can find little comment on this bruit in medical literature The late Sir B. W. Richardson ${ }^{3}$ drew attention to this cardiopulmonary sound under the title of An Auscultatory Sound produced by the Action of the Heart on a portion of the Lung, and recorded three cases which had come under his notice. All these cases ended fatally, and Richardson was from this led to consider that the sign might have some serious significance. In each case the murmur was heard on the left side of the chest, in the neighbourhood of the nipple, and post mortem a piéce of lung was found to be drawn down between the left ventricle and the thoracic wall, where it was held by adhesions. In one of the cases the pericardium was also adherent to the lung. Woillez, ${ }^{4}$ in reporting a case of thoracic deformity, notes that the vesicular respiratory sound was reinforced at each pulsation or dilatation of the aorta, and refers to Richardson's paper for examples of a similar modification of the breath sounds. Richardson's cases are still referred to, and apparently few cases of this common physical sign have been recorded.

Before the introduction of instruments for auscultation, and even up to the time when the binaural stethoscope came into use, this sign would probably have escaped recognition except by the masters of auscultation. Now that we have means which are in the reach of all for intensifying the chest sounds, it becomes more necessary to call attention to sounds which may mislead the auscultator. Most physicians with experience of chest diseases must have noticed this sign frequently, and have referred it to its proper cause. I know that this is so with some of our best known specialists. But amongst the greater number of practitioners to whom I have mentioned or demonstrated this respiratory "whiff," its occurrence seems to have been unsuspected.

The intensity of the sound varies considerably. Sometimes it is only heard by careful attention, and would be easily overlooked; at others it may even be heard at some distance from the patient (as in Case Ix). It is in the more obvious cases that the sign is the most misleading.

NotE.-Since the above article was written, a new work on Diseases of the Lung has been published (Diseases of the Lung by Kingston Fowler, M.D., and Rickman Godlee F.R.C.S.), in which this respiratory "whiff" is mentioned. Dr. Fowler, however, appears to consider that it occurs only in cases of tuberculosis of the lung; the cases recorded in this paper show that this is not the case.

\section{REFERENCES} 1 BRITISH MEDICAL JoURNAL, March 23,1895, p. 645.22 A case resembling
this very closely is published in the Lyon Medical for September, 1897 (t. Ixxxvi), p. 39, by Dr. L. Bonnet under the title "Bruits Pulmonaires (t. Ixxxvi), p. 39, by Dr. L. Bonnet under the title "Bruits Pulmonaires Rythmés par le Cœur." 3 Medical 